\title{
Construction of a prognosis-associated long noncoding RNA-mRNA network for multiple myeloma based on microarray and bioinformatics analysis
}

\author{
FANG-XIAO ZHU ${ }^{1}$, XIAO-TAO WANG ${ }^{1}$, ZHI-ZHONG YE ${ }^{2}$, ZHAO-PING GAN $^{3}$ and YONG-RONG LAI ${ }^{3}$ \\ ${ }^{1}$ Department of Rheumatology and Immunology, The Second Affiliated Hospital of Guilin Medical University, \\ Guilin, Guangxi 541001; ${ }^{2}$ Shenzhen Futian Hospital for Rheumatic Diseases, Shenzhen, Guangdong 518040; \\ ${ }^{3}$ Department of Hematology, The First Affiliated Hospital of Guangxi Medical University, \\ Nanning, Guangxi 530021, P.R. China
}

Received October 26, 2018; Accepted April 10, 2019

DOI: $10.3892 / \mathrm{mmr} .2020 .10930$

\begin{abstract}
At present, the association between prognosis-associated long noncoding RNAs (lncRNAs) and mRNAs is yet to be reported in multiple myeloma (MM). The aim of the present study was to construct prognostic models with lncRNAs and mRNAs, and to map the interactions between these lncRNAs and mRNAs in MM. LncRNA and mRNA data from 559 patients with MM were acquired from the Genome Expression Omnibus (dataset GSE24080), and their prognostic values were calculated using the survival package in $\mathrm{R}$. Multivariate Cox analysis was used on the top 20 most significant prognosis-associated mRNAs and lncRNAs to develop prognostic signatures. The performances of these prognostic signatures were tested using the survivalROC package in $\mathrm{R}$, which allows for time-dependent receiver operator characteristic (ROC) curve estimation. Weighted correlation network analysis (WGCNA) was conducted to investigate the associations between IncRNAs and mRNAs, and a lncRNA-mRNA network was constructed using Cytoscape software. Univariate Cox regression analysis identified 39 lncRNAs and 1,445 mRNAs that were significantly associated with event-free survival of MM patients. The top 20 most significant survival-associated lncRNAs and mRNAs were selected as candidates for analyzing independent MM prognostic factors. Both signatures could be used to separate patients into two groups with distinct outcomes. The areas under the ROC curves were 0.739 for the lncRNA signature and 0.732 for the mRNA signature. In the lncRNA-mRNA network, a total of 143 mRNAs were positively or negatively associated with 23 prognosis-associated lncRNAs.
\end{abstract}

Correspondence to: Professor Yong-Rong Lai, Department of Hematology, The First Affiliated Hospital of Guangxi Medical University, 6 Shuangyong Road, Nanning, Guangxi 530021, P.R. China E-mail: laiyongrong@hotmail.com

Key words: multiple myeloma, microarray, prognosis index, long noncoding RNA-mRNA network, bioinformatics
NCRNA00201, LOC115110 and RP5-968J1.1 were the most dominant drivers. The present study constructed a model that predicted prognosis in MM and formed a network with the corresponding prognosis-associated mRNAs, providing a novel perspective for the clinical diagnosis and treatment of MM, and suggesting novel directions for interpreting the mechanisms underlying the development of MM.

\section{Introduction}

Long noncoding RNAs (lncRNAs) are a class of RNA ( $>200$ nucleotides in length) that cannot synthesize proteins (1-4). These biomolecules are involved in post-transcriptional regulation (5-8), and are abnormally expressed in multiple types of solid tumor and hematopoietic malignancy; lncRNAs are involved in both carcinogenesis and tumor suppression (9-13).

The expression levels of several lncRNAs have been reported in multiple myeloma $(\mathrm{MM})$; their clinical significance, biological functions and potential molecular mechanisms in the disease have also been investigated (14-16). MM is the second most frequent hematological malignancy, and accounts for $\sim 10 \%$ of all such malignancies (17-22). Immunomodulatory drugs (such as lenalidomide and pomamide), proteasome inhibitors (such as bortezomib and carfilzomib) and monoclonal antibodies have significantly increased the survival rate of patients with MM over the past decade (23-25); however, the treatment of relapsed and partially refractory patients remains challenging. The pathogenesis and progression of MM involve complex and heterogeneous genomic alterations (26-30), including modifications that are influenced by lncRNAs.

Certain lncRNAs have been documented to serve an important role in the progression of $\mathrm{MM}$, and can be used as indicators of patient prognosis. For example, metastasis-associated lung adenocarcinoma transcript 1 (MALAT1) is overexpressed in MM tissues and various MM cell lines; upregulation of MALAT1 is significantly associated with poor prognosis, including overall survival (OS) and progression-free survival (PFS) (31-33). Nuclear paraspeckle assembly transcript 1 (NEAT1) has also been reported to serve a pivotal role in promoting MM, and its elevated expression is 
closely associated with poor prognosis $(34,35)$. The upregulation of urothelial cancer associated 1 (UCA1) (36), protein disulfide isomerase family A member 3 pseudogene 1 (PDIA3P) (37), H19 (38), colon cancer associated transcript 1 (CCAT1) (39) and colorectal neoplasia differentially expressed $(C R N D E)$ (40) are closely associated with poor prognosis in $\mathrm{MM}$; these genes may be used as future indicators in the clinical prognosis of patients with MM. Despite the large numbers of lncRNAs, only a small number have been associated with the prognosis of MM; however, numerous as-yet-undiscovered lncRNAs may also be associated with the progression of MM and patient outcome. Additionally, the predictive ability of a single indicator is limited; a prognostic signature composed of numerous indicators is required to conduct a comprehensive clinical evaluation of tumor prognosis. Prognostic models that combine several indicators have been used in a wide variety of tumors (41-45); however, a prognostic model for MM comprising lncRNAs is yet to be reported.

The present study screened gene chips with expression data from patients with MM and selected prognostic lncRNAs and mRNAs. The associations between the prognostic lncRNAs and mRNAs were mapped, and certain indicators were selected to construct a prognostic model. The MM prognostic model presented in the current study may provide novel insight and directions for the clinical treatment of MM in the future.

\section{Materials and methods}

Data acquisition. The microarray gene expression profiling data from the bone marrow of newly diagnosed patients with MM that had not been treated was obtained from the Genome Expression Omnibus (GEO) dataset $(46,47)$ with accession number GSE24080 (48). The data from 559 patients with MM were included for further survival analysis. To separate lncRNAs and mRNAs, probes from the Affymetrix HG-U133_Plus_2.0 array were re-annotated. For genes that matched $>1$ probe, the expression values of all the measurements were calculated using an average value of the probes. The IncRNAs were extracted according to their Refseq database label (Release 93) (49) and Ensembl annotations (Release version 96) (50).

Survival analysis. Event-free survival (EFS) generally provides more reliable endpoint information for survival analysis (51); thus, it was selected as the survival analysis endpoint in the present study. Univariate Cox analysis was conducted to select prognosis-associated mRNAs and lncRNA using the survival package (version 2.44-1.1) in $\mathrm{R}$ (version 3.4.4) ( $\mathrm{R})$. $\mathrm{P}<0.005$ was considered to be statistically significant (52). Kaplan-Meier plot was generated to observe the survival status between different survival associated mRNA and lncRNA expression levels.

Gene functional enrichment analyses. To further investigate the potential molecular mechanisms of the top 20 prognosis-associated mRNAs, the biological processes, which were acquired from gene ontology and Kyoto Encyclopedia of Genes and Genomes (Release 87.1) (KEGG) pathways (53-55) were examined based on enrichment analysis using the Clusterprofiler package (version 3.10.1) in R (56).
Protein-protein interaction (PPI) networks were developed to explore the associations between each gene using the GeneMANIA plug-in in Cytoscape version 3.6.1 (57,58).

Prognostic signature construction. As the prognostic value of a single indicator is limited, prognostic signatures were produced that combined multiple indicator candidates. Multivariate Cox analysis was performed on the top 20 most significant prognosis-associated mRNAs and lncRNAs to develop prognostic signatures. The performances of these prognostic signatures were tested using the survivalROC (version 1.0.3) package in $\mathrm{R}$, which provides time-dependent receiver operator characteristic (ROC) curve estimation $(59,60)$. The area under curve (AUC) was calculated at 75 months, as fewer events occurred after this point.

Weighted correlation network analysis (WGCNA). As lncRNAs cannot be transcribed into proteins, their functional effects are frequently achieved by targeting mRNAs. To investigate the associations between lncRNAs and mRNAs, WGCNA was conducted using the WGCNA package (version 1.63) in $\mathrm{R}(61,62)$. The mRNAs were separated into modules, and correlations between the prognostic mRNAs and IncRNAs were calculated. A lncRNA-mRNA axis was identified when an association coefficient $>0.4$ was obtained. The potential regulatory network was constructed using Cytoscape software.

\section{Results}

Prognosis-associated lncRNAs and mRNAs. The present study included 559 patients with MM from the GSE24080 (48) dataset. This dataset was collected and distributed by the Myeloma Institute for Research and Therapy at the University of Arkansas for Medical Sciences. Dichotomized OS and EFS values were examined based on a 2-year milestone cutoff. A univariate Cox regression analysis identified 39 lncRNAs and 1,445 mRNAs that were significantly associated with the EFS of patients with MM (Fig. 1A and B). The top 20 most significant survival-associated lncRNAs and mRNAs are presented in the form of forest plots (Fig. 1C and D; Table I).

Functional enrichment analyses. Enrichment analyses for the top 20 prognosis-associated mRNAs were conducted to identify risk pathways and biological functions associated with these prognostic genes (Table II). As presented in Fig. 2A, a number of cell cycle-associated biological processes were identified, including signal transduction by a p53-class mediator, cell cycle $\mathrm{G} 2 / \mathrm{M}$ transition and mitotic cell cycle G2/M transition. These categories are also closely involved in tumor proliferation. The PPI network revealed that these genes were closely associated with each other (Fig. 2B). It was also observed that these prognostic genes were associated with homologous recombination (Table II). Collectively, the present results suggested that these genes may serve an important role in the pathogenesis of MM.

Development of the prognostic signatures. The top 20 most significant survival-associated lncRNAs (Fig. 3) and mRNAs (Fig. 4) were selected as candidates for analyzing independent MM prognostic factors. Multivariate Cox regression analyses 

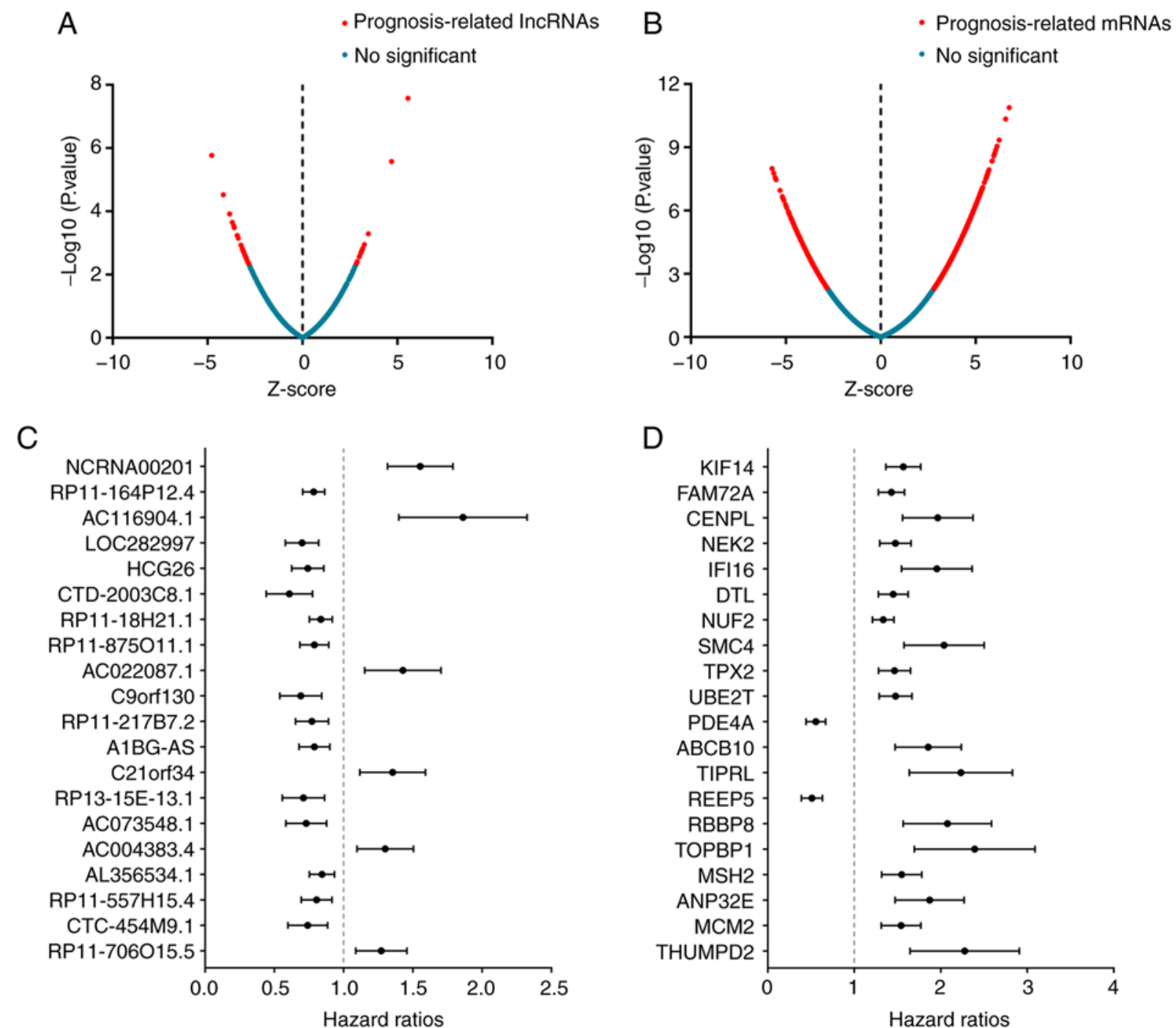

Figure 1. Survival-associated lncRNAs and mRNAs in multiple myeloma. (A) Red dots indicate lncRNAs whose expression levels are significantly associated with patient survival, whereas blue dots indicate lncRNAs that do not exhibit an association. $\mathrm{P}<0.005$ was set as the threshold. (B) Red dots indicate mRNAs whose expression levels are significantly associated with patient survival, whereas blue dots indicate mRNAs that do not exhibit an association. $\mathrm{P}<0.005$ was set as the threshold. (C) Top 20 most significantly survival-associated lncRNAs. (D) Top 20 most significant survival-associated mRNAs. LncRNA, long noncoding RNA.

were conducted to develop two prognostic signatures based on lncRNAs and mRNAs (Fig. 5A and B). Both signatures could be used to separate patients into two groups with distinct outcomes. The AUCs of ROC curves were 0.739 for the lncRNA signature and 0.732 for the mRNA signature (Fig. 5C and D). These findings suggested that the two risk scores exhibited a moderate power to predict the survival of patients with MM.

Construction of the lncRNAs-mRNAs network. WGCNA was used to separate prognosis-associated mRNAs into groups, and to explore the associations between lncRNAs and mRNAs (Fig. 6). The lncRNA-mRNA network provided novel insight into the regulatory mechanisms associated with the progression of MM (Fig. 7). A total of 143 mRNAs were positively or negatively associated with 23 prognosis-related lncRNAs. NCRNA00201, LOC115110 and RP5-968J1.1 appeared to be the most dominant drivers, as they possessed the highest number of connected genes.

\section{Discussion}

Currently, there is no precise method to assess the prognosis of patients with MM. In the present study, the expression data from a gene chip containing genomic samples from 559 patients with MM were analyzed, and predictive models were constructed based on the lncRNA and mRNA expression profiles. Of note, it was observed that pools of prognostic candidates exhibited greater predictive power than individual indicators. There may also be a targeting relationship between the prognosis-associated lncRNAs and mRNAs. As a previous report has contraindicated the use of a lncRNA prediction model for the prognosis of MM, the present study provides novel insight for the clinical diagnosis and treatment of MM (63).

Previously, two other research groups have analyzed the gene chip data of GSE24080 to obtain MM prognosis-associated lncRNAs using different statistical methods. Zhou et al (64) randomly split the MM cohort into a training 
Table I. Top 20 most significant survival-associated mRNAs and lncRNAs.

A, mRNAs

\begin{tabular}{lccc}
\hline Gene symbol & HR & Z-score & P-value \\
\hline KIF14 & 1.559189 & 6.768521 & $1.30 \times 10^{-11}$ \\
FAM72A & 1.425627 & 6.586882 & $4.49 \times 10^{-11}$ \\
CENPL & 1.938061 & 6.233485 & $4.56 \times 10^{-10}$ \\
NEK2 & 1.468169 & 6.129078 & $8.84 \times 10^{-10}$ \\
IFI16 & 1.926689 & 6.126442 & $8.99 \times 10^{-10}$ \\
DTL & 1.443987 & 6.061892 & $1.35 \times 10^{-09}$ \\
NUF2 & 1.330607 & 6.004863 & $1.91 \times 10^{-09}$ \\
SMC4 & 2.003832 & 5.957470 & $2.56 \times 10^{-09}$ \\
TPX2 & 1.458392 & 5.867954 & $4.41 \times 10^{-09}$ \\
UBE2T & 1.469349 & 5.864287 & $4.51 \times 10^{-09}$ \\
PDE4A & 0.548218 & -5.729731 & $1.01 \times 10^{-08}$ \\
ABCB10 & 1.828576 & 5.704206 & $1.17 \times 10^{-08}$ \\
TIPRL & 2.179489 & 5.665706 & $1.46 \times 10^{-08}$ \\
REEP5 & 0.500858 & -5.643577 & $1.67 \times 10^{-08}$ \\
RBBP8 & 2.034743 & 5.624249 & $1.86 \times 10^{-08}$ \\
TOPBP1 & 2.324429 & 5.605628 & $2.08 \times 10^{-08}$ \\
MSH2 & 1.537154 & 5.602649 & $2.11 \times 10^{-08}$ \\
ANP32E & 1.843312 & 5.600536 & $2.14 \times 10^{-08}$ \\
MCM2 & 1.529821 & 5.596079 & $2.19 \times 10^{-08}$ \\
THUMPD2 & 2.218271 & 5.567595 & $2.58 \times 10^{-08}$ \\
\hline & & & \\
\hline
\end{tabular}

$\mathrm{B}, \operatorname{lncRNAs}$

\begin{tabular}{lcrc}
\hline Gene symbol & HR & Z-score & P-value \\
\hline NCRNA00201 & 1.541349 & 5.562407 & $2.66 \times 10^{-08}$ \\
RP11-164P12.4 & 0.781350 & -4.785449 & $1.71 \times 10^{-06}$ \\
AC116904.1 & 1.823522 & 4.696971 & $2.64 \times 10^{-06}$ \\
LOC282997 & 0.692999 & -4.174333 & $2.99 \times 10^{-05}$ \\
HCG26 & 0.734874 & -3.843160 & $1.21 \times 10^{-04}$ \\
CTD-2003C8.1 & 0.592561 & -3.689247 & $2.25 \times 10^{-04}$ \\
RP11-18H21.1 & 0.832661 & -3.620982 & $2.93 \times 10^{-04}$ \\
RP11-875O11.1 & 0.784430 & -3.592916 & $3.27 \times 10^{-04}$ \\
AC022087.1 & 1.410099 & 3.472571 & $5.15 \times 10^{-04}$ \\
C9orf130 & 0.679642 & -3.442218 & $5.77 \times 10^{-04}$ \\
RP11-217B7.2 & 0.765044 & -3.388514 & $7.03 \times 10^{-04}$ \\
A1BG-AS & 0.783840 & -3.372035 & $7.46 \times 10^{-04}$ \\
C21orf34 & 1.340267 & 3.260104 & $1.11 \times 10^{-03}$ \\
RP13-15E13.1 & 0.698713 & -3.243736 & $1.18 \times 10^{-03}$ \\
AC073548.1 & 0.720060 & -3.176108 & $1.49 \times 10^{-03}$ \\
AC004383.4 & 1.289903 & 3.172203 & $1.51 \times 10^{-03}$ \\
AL356534.1 & 0.840370 & -3.170147 & $1.52 \times 10^{-03}$ \\
RP11-557H15.4 & 0.799831071 & -3.165730 & $1.55 \times 10^{-03}$ \\
CTC-454M9.1 & 0.731592407 & -3.144922 & $1.66 \times 10^{-03}$ \\
RP11-706O15.5 & 1.263062805 & 3.144145 & $1.67 \times 10^{-03}$ \\
\hline
\end{tabular}

HR, hazard ratio; lncRNA, long noncoding RNA. dataset $(n=280)$ and a testing dataset $(n=279)$. Univariate regression analysis identified 59 lncRNAs that were associated with the OS of patients. Only four of those lncRNAs (RP4-803J11.2, RP1-43E13.2, RP11-553L6.5 and ZFY-AS1) were reported to exhibit a predictive effect following multivariate regression analysis. These results were inconsistent with a study by $\mathrm{Hu}$ et al (63), which identified 176 lncRNAs from the GSE24080 and GSE57317 datasets that appeared to be associated with patient survival. The $\mathrm{Hu}$ et al study employed Kaplan-Meier analysis to determine the prognostic influence of lncRNAs, identifying 176 lncRNAs, including RP1-286D6.1, AC008875.2, MTMR9L, AC069360.2 and AL512791.1, as prospective markers for assessing the prognosis of patients with MM. Of note, none of the aforementioned lncRNAs overlapped with the top 20 prognosis-associated lncRNAs identified in the present study, which conducted survival analysis using the survival package in R. Among the top 20 prognosis-associated lncRNAs in the present study, a number were identified as risk factors, including NCRNA00201, AC116904.1, AC022087.1, C21ORF34, AC004383.4 and RP11-706015.5. The remaining 14 lncRNAs may protect against MM. The use of different statistical tools may partially explain the variations in the lncRNAs identified in each study. In the previously published studies that analyzed GSE24080, Hu et al (63) did not conduct ROC analysis to determine the prognostic values of their lncRNAs, whereas Zhou et al (64) reported four lncRNAs (RP4-803J11.2, RP1-43E13.2, RP11-553L6.5 and ZFY-AS1) together generated an AUC of 0.682 to represent prognostic performance. In the present study, ROC analysis was performed using the survivalROC package in $\mathrm{R}$, resulting in an AUC of 0.739, more favorable than that in Zhou et al (64).

None of the lncRNAs in the presently reported prognostic model have been previously investigated in MM. At present, the majority of the top 20 prognosis-associated lncRNAs have not been reported in any disease. Only three of the lncRNAs have been previously studied, NCRNA00201, HCG26 and C21ORF34.

NCRNA00201, also termed heterogeneous nuclear ribonucleoprotein $U$ processed transcript, has been studied in patients with a submicroscopic deletion at 1q43q44. NCRNA00201 is in a critical deleted region of $1 q 44$ (65). It is expressed in various normal tissues, including brain tissues; the highest expression levels of NCRNA00201 have been observed in the cerebellum (65). As patients with a submicroscopic deletion at $1 \mathrm{q} 43 \mathrm{q} 44$ present with intellectual disability, microcephaly, craniofacial anomalies, seizures, limb anomalies and corpus callosum abnormalities, NCRNA00201 may serve a role in these diseases; however, 9 out of 11 patients with a submicroscopic deletion at 1q43q44 did not present with microcephaly or corpus callosum abnormalities, and possessed a small deletion containing NCRNA00201 (65). This study revealed that NCRNA00201 does not affect microcephaly or corpus callosum abnormalities, but that it is a prognostic candidate for intellectual disability and seizures (65).

The potential biological functions of NCRNA00201 have also been documented in pancreatic ductal adenocarcinoma (PDAC); it was significantly overexpressed in PDAC tissues and cell lines compared with noncancerous pancreatic controls. Upregulated levels of NCRNA00201 were associated with poorer prognosis in patients with PDAC. 
Table II. The top 10 most significant biological processes and Kyoto Encyclopedia of Genes and Genomes pathway.

\begin{tabular}{|c|c|c|c|c|c|c|}
\hline Category & ID & Description & P-value & Q-value & Genes & Count \\
\hline Biological process & GO:0000077 & DNA damage checkpoint & $5.56 \times 10^{-07}$ & 0.000101 & $\begin{array}{l}\text { DTL, TIPRL, RBBP8, } \\
\text { TOPBP1, MSH2 }\end{array}$ & 5 \\
\hline Biological process & GO:0031570 & DNA integrity checkpoint & $7.35 \times 10^{-07}$ & 0.000101 & $\begin{array}{l}\text { DTL, TIPRL, RBBP8, } \\
\text { TOPBP1, MSH2 }\end{array}$ & 5 \\
\hline Biological process & GO:0010389 & $\begin{array}{l}\text { Regulation of } \mathrm{G} 2 / \mathrm{M} \\
\text { transition of mitotic cell cycle }\end{array}$ & $1.68 \times 10^{-06}$ & 0.000148 & $\begin{array}{l}\text { KIF14, NEK2, DTL, } \\
\text { TPX2, TOPBP1 }\end{array}$ & 5 \\
\hline Biological process & GO: 1902749 & $\begin{array}{l}\text { Regulation of cell cycle } \\
\text { G2/M phase transition }\end{array}$ & $2.16 \times 10^{-06}$ & 0.000148 & $\begin{array}{l}\text { KIF14, NEK2, DTL, } \\
\text { TPX2, TOPBP1 }\end{array}$ & 5 \\
\hline Biological process & GO:0000075 & Cell cycle checkpoint & $3.49 \times 10^{-06}$ & 0.000178 & $\begin{array}{l}\text { DTL, TIPRL, RBBP8, } \\
\text { TOPBP1, MSH2 }\end{array}$ & 5 \\
\hline Biological process & GO:0000819 & Sister chromatid segregation & $3.88 \times 10^{-06}$ & 0.000178 & $\begin{array}{l}\text { KIF14, CENPL, NEK2, } \\
\text { NUF2, SMC4 }\end{array}$ & 5 \\
\hline Biological process & GO:0000086 & $\begin{array}{l}\mathrm{G} 2 / \mathrm{M} \text { transition of mitotic } \\
\text { cell cycle }\end{array}$ & $5.61 \times 10^{-06}$ & 0.00022 & $\begin{array}{l}\text { KIF14, NEK2, DTL, } \\
\text { TPX2, TOPBP1 }\end{array}$ & 5 \\
\hline Biological process & GO:0044839 & $\begin{array}{l}\text { Cell cycle } \mathrm{G} 2 / \mathrm{M} \text { phase } \\
\text { transition }\end{array}$ & $6.67 \times 10^{-06}$ & 0.000229 & $\begin{array}{l}\text { KIF14, NEK2, DTL, } \\
\text { TPX2, TOPBP1 }\end{array}$ & 5 \\
\hline Biological process & GO:0031572 & G2 DNA damage checkpoint & $7.73 \times 10^{-06}$ & 0.000233 & DTL, RBBP8, TOPBP1 & 3 \\
\hline Biological process & GO:0072331 & $\begin{array}{l}\text { Signal transduction by p } 53 \\
\text { class mediator }\end{array}$ & $8.48 \times 10^{-06}$ & 0.000233 & $\begin{array}{l}\text { IFI16, TPX2, RBBP8, } \\
\text { TOPBP1, MSH2 }\end{array}$ & 5 \\
\hline KEGG pathway & hsa03440 & Homologous recombination & $8.06 \times 10^{-04}$ & 0.007636 & RBBP8, TOPBP1 & 2 \\
\hline
\end{tabular}

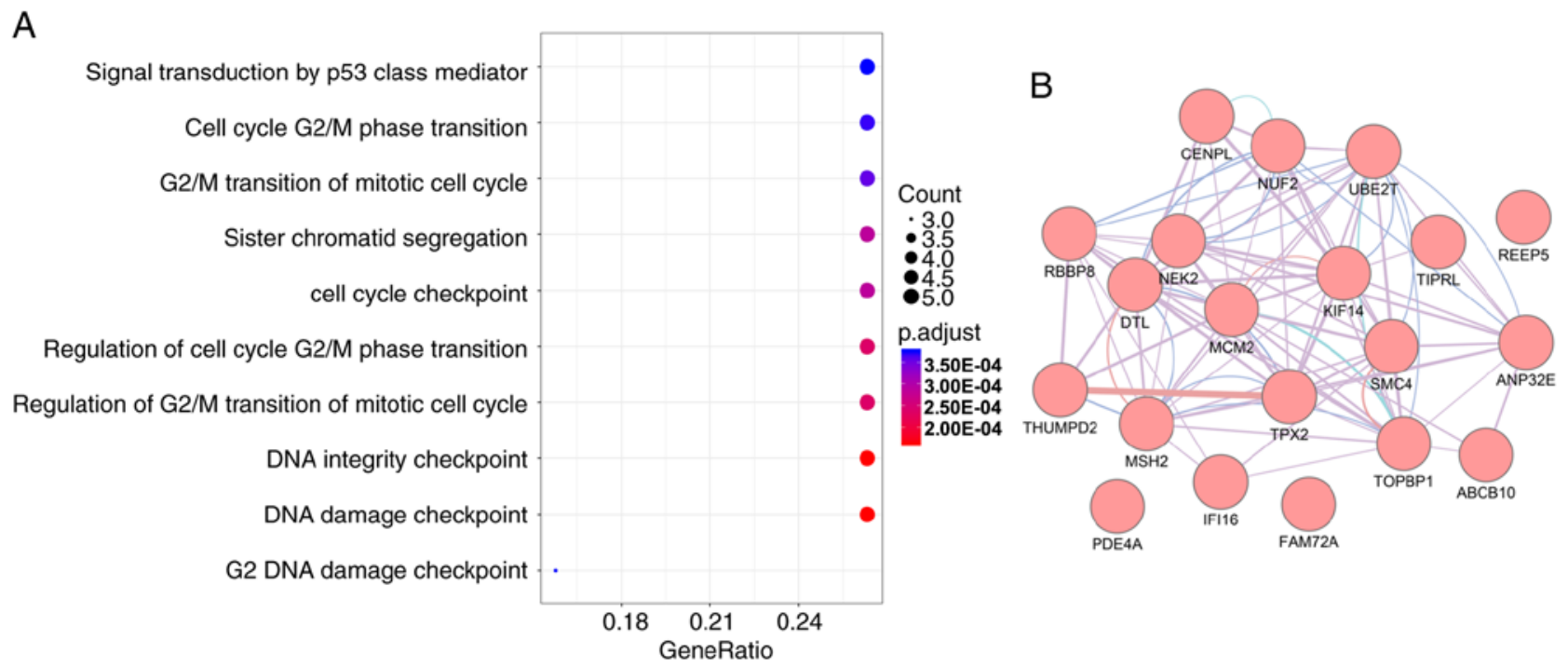

Figure 2. Biological processes and protein-protein interactions of the top 20 survival-associated mRNAs in multiple myeloma. (A) Biological processes in gene ontology. (B) Interactions between the top 20 most significant survival-associated mRNAs. Purple, blue, red and green connections indicate co-expression, co-localization, physical interaction and pathway, respectively.

Suppression of NCRNA00201 inhibited cell proliferation, invasion and migration in PDAC cell lines (66). These results indicated that NCRNA00201 served an important role in the tumorigenesis and progression of PDAC (66). NCRNA00201 may serve a similar role in MM, as increased NCRNA00201 levels were closely associated with poor survival in patients with MM. NCRNA00201 may be a risk factor for poor prognosis; however, this finding should be validated in additional cohorts.
The MM prognosis-associated lncRNA HCG26 has also been reported in other diseases. This lncRNA exhibited dysregulated expression in the blood of patients that had suffered an ischemic stroke (67). HCG26 was also reported to be associated with polycystic ovary syndrome (PCOS) (68). Increased HCG26 levels in patients with PCOS were related to antral follicle count. HCG26 knockdown in KGN cells suppressed cell proliferation and cell-cycle progression, and enhanced aromatase gene expression and estradiol production, suggesting that HCG26 

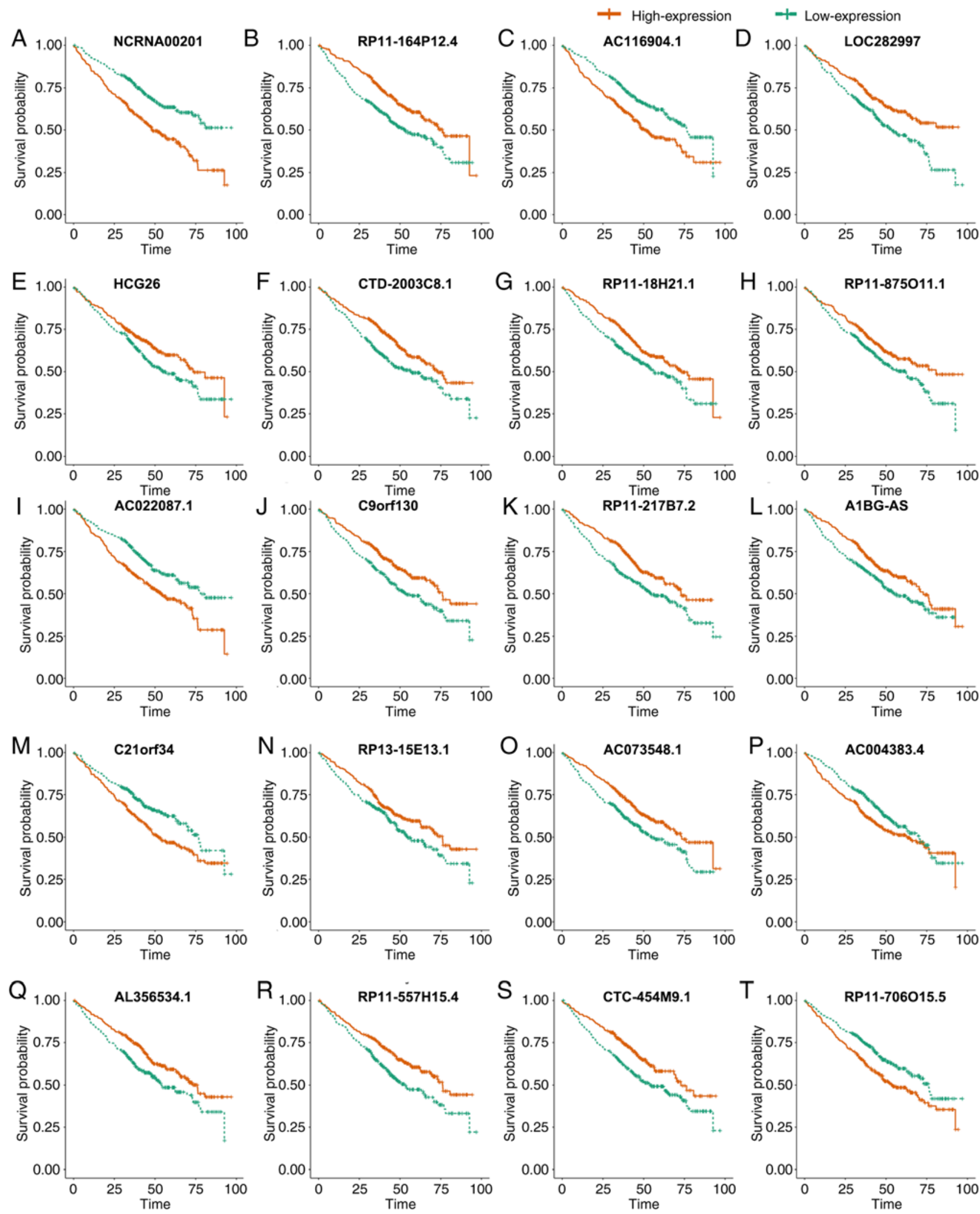

Figure 3. Kaplan-Meier analysis of the top 20 most significantly survival-associated long noncoding RNAs in multiple myeloma. (A) NCRNA00201.(B) RP11-164P12.4 (C) AC116904.1. (D) LOC282997. (E) HCG26. (F) CTD-2003C8.1. (G) RP11-18H21.1. (H) RP11-875O11.1. (I) AC022087.1. (J) C9orf130. (K) RP11-217B7.2. (L) A1BG-AS. (M) C21orf34. (N) RP13-15E13.1. (O) AC073548.1. (P) AC004383.4 (Q) AL356534.1. (R) RP11-557H15.4. (S) CTC-454M9.1. (T) RP11-706O15.5.

may contribute towards the pathogenesis of PCOS (68). HCG26 has also been reported to be associated with nasopharyngeal carcinoma. A genome-wide study of copy number variation associated with nasopharyngeal carcinoma in a Malaysian-Chinese cohort identified candidate loci copy number variations at $11 \mathrm{q} 14.3$ and $6 \mathrm{p} 21.3$ (including a copy number variant region with $H C G 26$ ), indicating that $H C G 26$ may serve a role in the development of nasopharyngeal carcinoma (69). In the present 

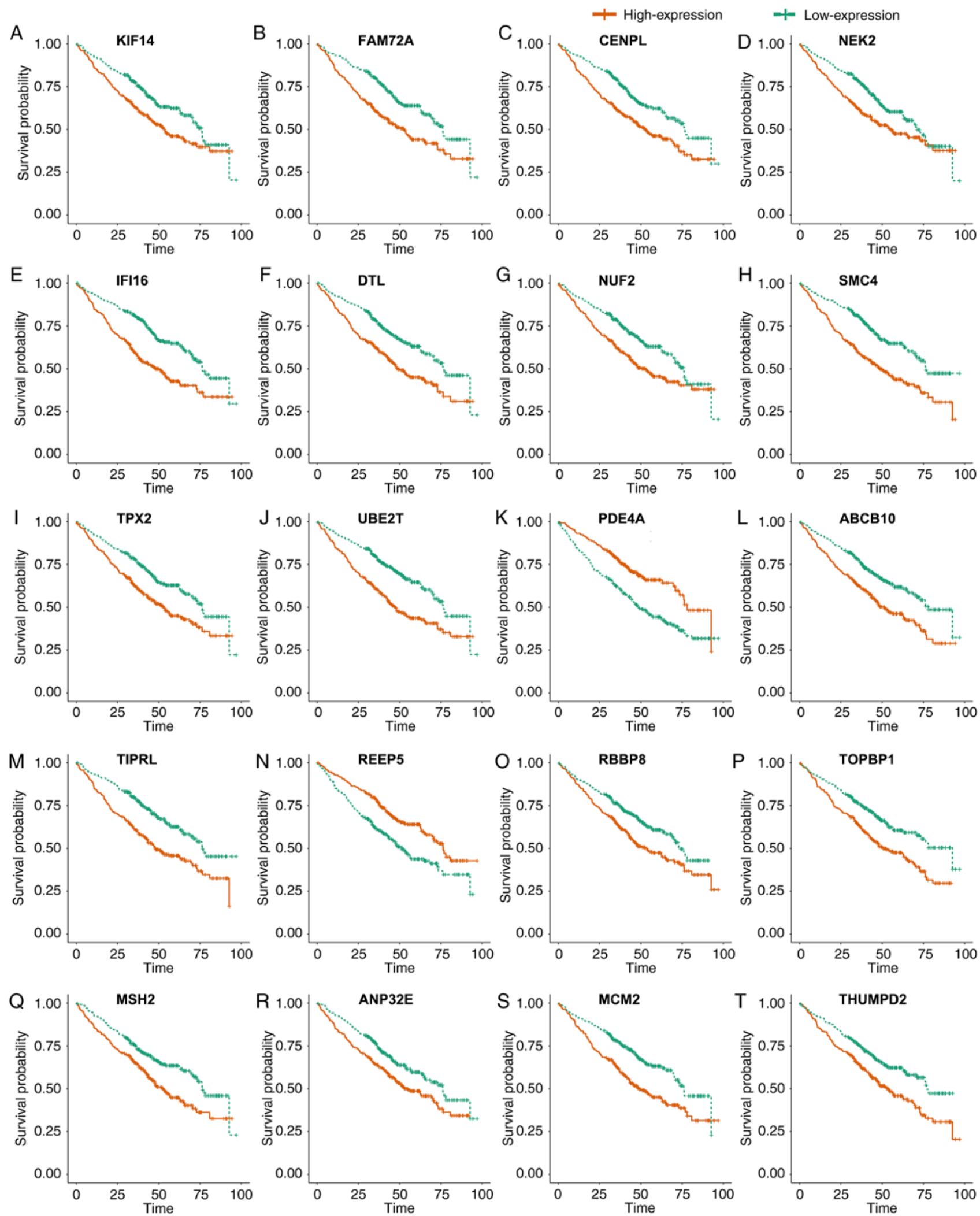

Figure 4. Kaplan-Meier analysis of the top 20 most significantly survival-associated mRNAs in multiple myeloma. (A) KIF14. (B) FAM72A. (C) CENPL. (D) NEK2. (E) IFI16. (F) DTL. (G) NUF2. (H) SMC4. (I) TPX2. (J) UBE2T. (K) PDE4A. (L) ABCB10. (M) TIPRL. (N) REEP5. (O) RBBP8. (P) TOPBP1. (Q) MSH2. (R) ANP32E. (S) MCM2. (T) THUMPD2.

study, HCG26 overexpression was associated with improved prognosis in MM, suggesting that it may act to protect against MM. The clinical roles and mechanisms of HCG26 in MM require further investigation.
The third previously reported lncRNA that exhibited potential prognostic value in MM was C21orf34. C21orf 34 has been studied for its role in blood pressure by the Hypertension Genetic Epidemiology Network; African 
A

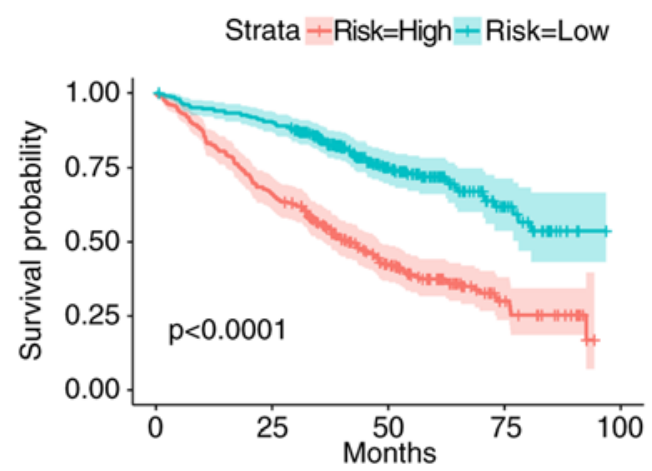

Number at risk
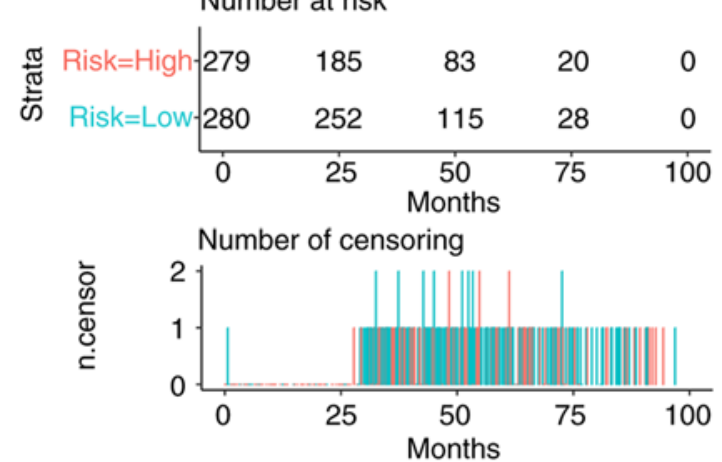

C

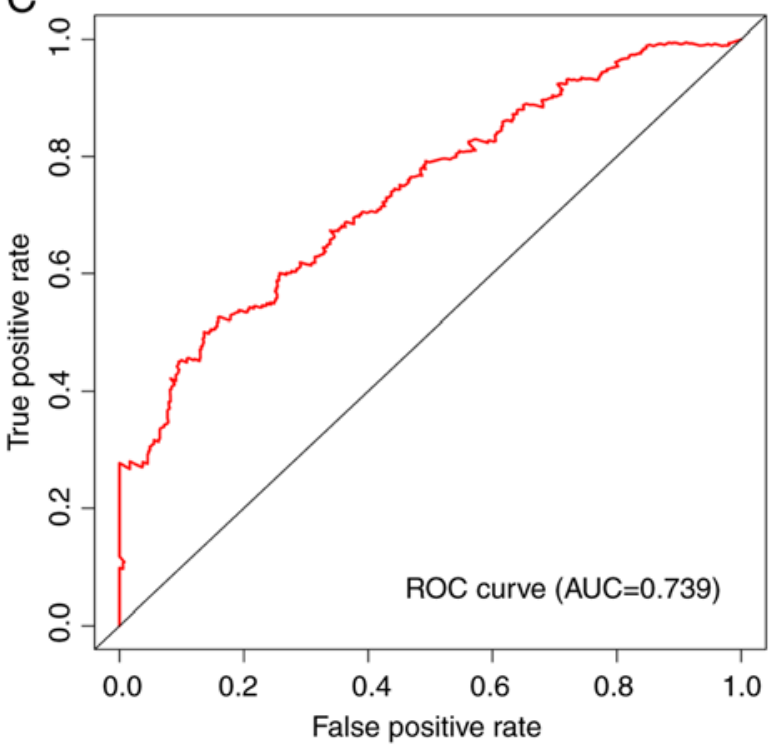

$\mathrm{B}$

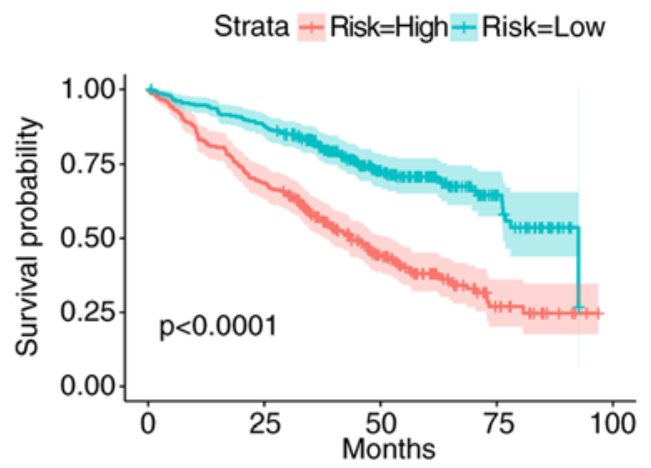

Number at risk

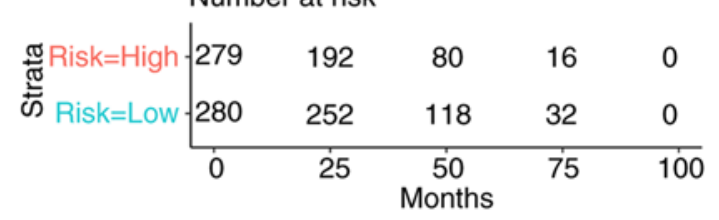

Number of censoring
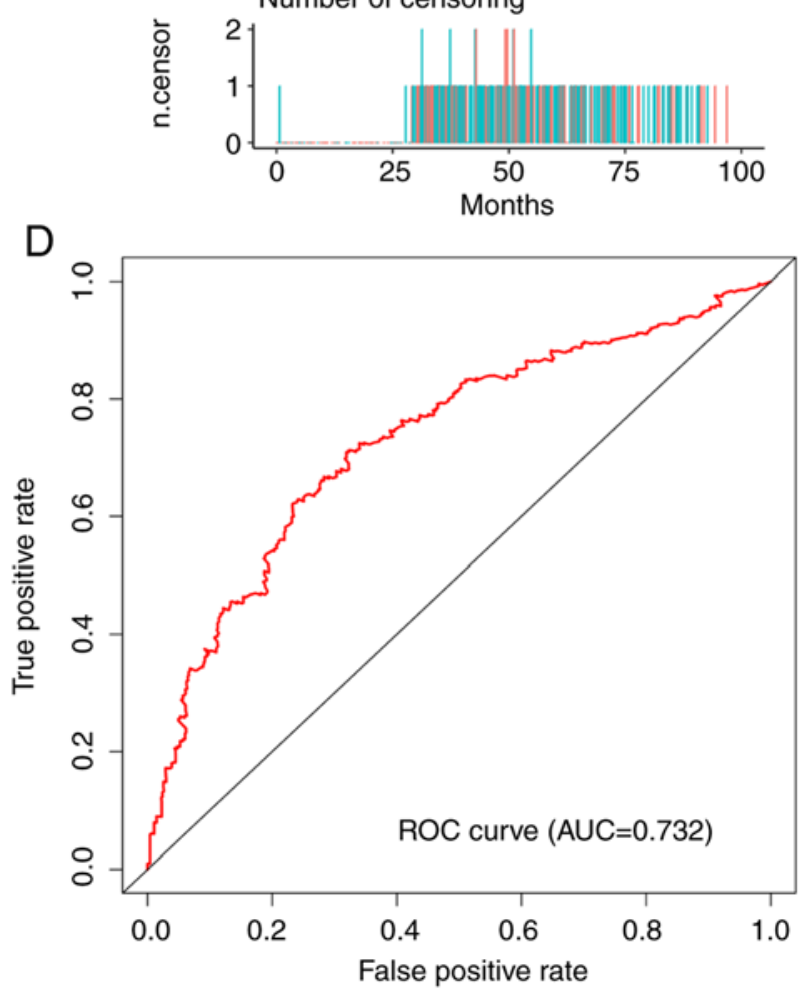

Figure 5. Prognostic signatures based on lncRNAs and mRNAs. (A) Kaplan-Meier analysis of the lncRNA-based risk score model predicts MM EFS. (B) Kaplan-Meier analysis of the mRNA-based risk score model predicts MM EFS. (C) ROC curve of the lncRNA-based risk score. (D) ROC curve of the mRNA-based risk score. EFS, event-free survival; IncRNA, long noncoding RNA; MM, multiple myeloma; ROC, receiver operating characteristic.

Americans and European Americans exhibited associations between blood pressure and intronic single nucleotide polymorphisms on chromosome 21q21.1 (70). The C2lorf34 gene was linked to African American patients, improving understanding of the pathophysiology of hypertension (70). C21orf34 has also been studied in malignancy; C21orf34, which is the host gene of microRNA-125b, was reported to be downregulated in human metastatic melanoma (71). The role of C2lorf34 in MM is yet to be determined. This study is the first to identify C21orf 34 as an MM prognostic indicator. Its increased expression levels may predict the improved survival of patients with MM, suggesting that it may act as a protective factor against MM. As the prognostic value of
C21orf34 was only determined via gene chip data mining, little is known regarding the functional role and mechanism of $C 21$ orf 34 in MM. Therefore, further investigation is required.

To investigate the potential functional implications of prognostic markers for the onset and progression of MM, various bioinformatics computational methods were combined. The most reliable prognostic biomarkers identified in the present study were actively involved in cell cycle-associated processes. Sustained and proliferative signaling has been increasingly acknowledged as a fundamental trait of cancer cells, so the present findings are not unexpected (72). Previous studies reported that cell cycle 

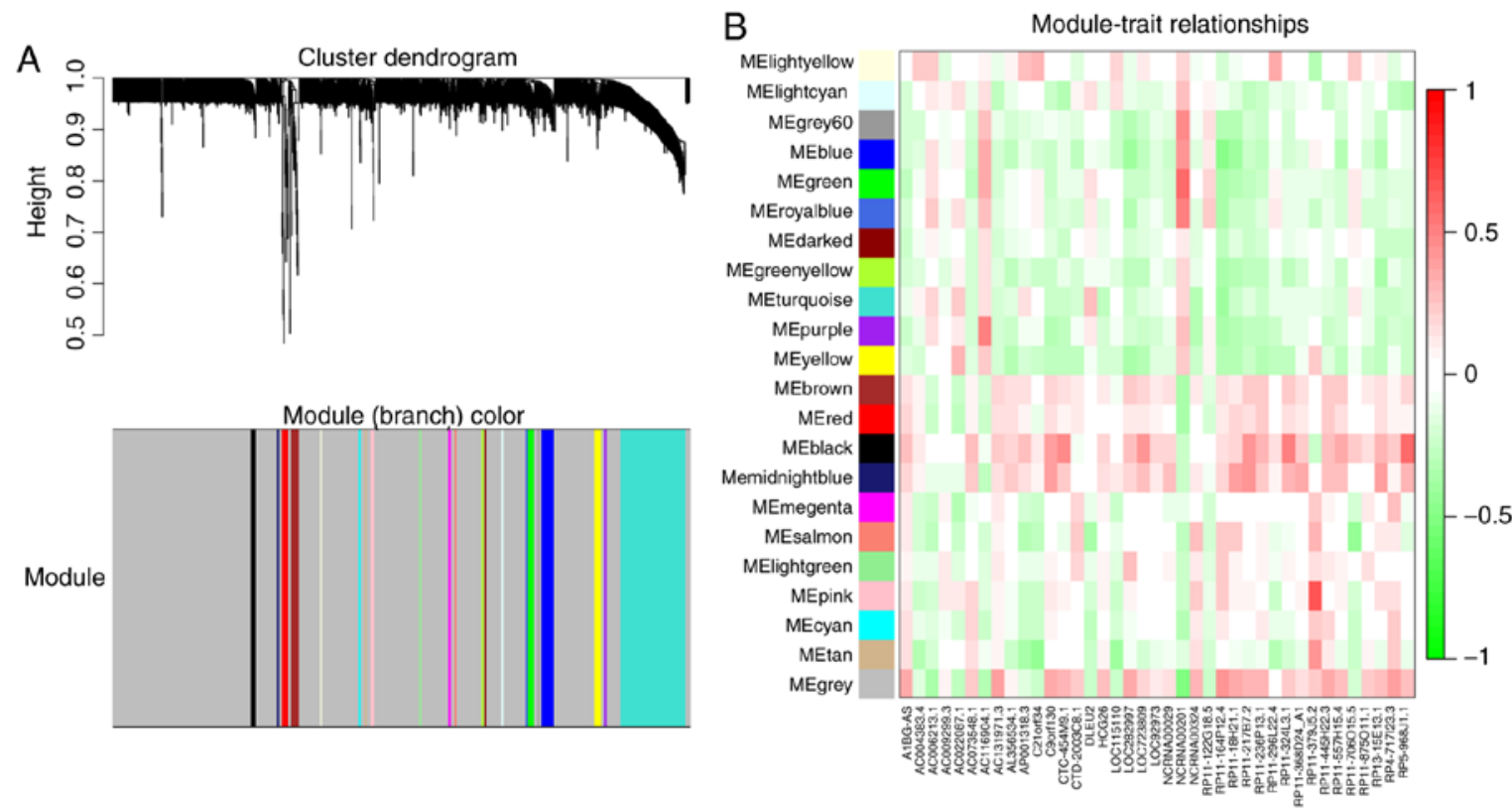

Figure 6. Weighted correlation network analysis. (A) Survival-associated genes in multiple myeloma were divided into modules. (B) Relationships between the long noncoding RNAs and mRNAs.

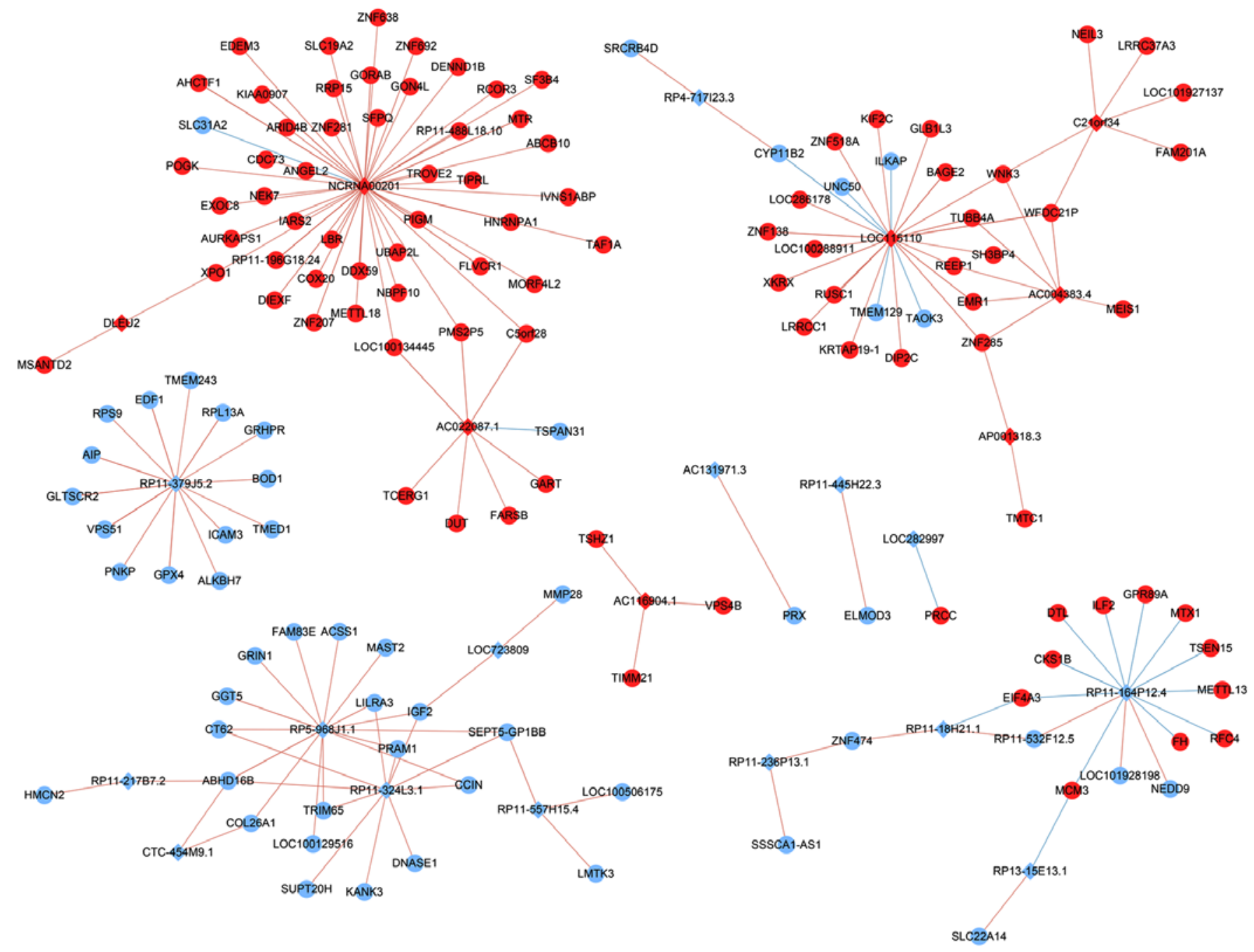

Figure 7. LncRNA-mRNA regulatory network. Red circles indicate risk-associated mRNAs; blue circles indicate protective mRNAs. Red squares indicate risk-associated lncRNAs; blue squares indicate protective lncRNAs. Red edges indicate positive associations; blue edges indicate negative associations. LncRNA, long noncoding RNA. 
interference may exert an antitumor function in MM $(73,74)$. As a result of the complex mechanisms of tumorigenesis and tumor progression, a single gene is unlikely to underpin poor prognosis in MM. Therefore, a lncRNA-mRNA network was proposed to comprehensively explore the molecular characteristics of MM. The WGCNA results indicated that there may also be targeting relationships between the prognosis-associated lncRNAs and mRNAs. These lncRNAs may exert their prognostic effects by targeting closely associated mRNAs. Investigations of IncRNA-based regulatory networks are limited, particularly from the perspective of prognosis. Ronchetti et al (75) previously proposed a network constructed by lncRNAs and miRNAs. Further research should be conducted into the functional relationships between mRNAs and lncRNAs.

Certain shortcomings in the present study should be stated. A total of 559 cases were included in this study; however, the reported findings should be confirmed in additional independent cohorts. Furthermore, the prognostic values of the lncRNAs in this study were investigated using a gene chip; this single detection method should be verified by other methods, such as reverse transcription-quantitative PCR. Additionally, the majority of the IncRNAs identified in our prognostic model have not been previously reported. Their specific clinical significance, biological functions and potential mechanisms of action should be studied in further experiments. Finally, the molecular associations between identified lncRNAs and mRNAs in the expression network should be further investigated. Additional experiments are required to determine whether the prognosis-associated lncRNAs serve a role in MM via their corresponding mRNA targets.

In conclusion, the present study constructed a model that is capable of predicting prognosis in $\mathrm{MM}$ and generated a network with corresponding prognosis-associated mRNAs. Of note, the clinical significance and function of the majority of the lncRNAs identified in the present study remain unknown. These results offer novel perspective for the clinical diagnosis and treatment of MM and suggest novel directions for investigating the mechanisms underlying the development of MM.

\section{Acknowledgements}

Not applicable.

\section{Funding}

The present study was supported in part by the National Nature Science Foundation of China (grant no. 81560024), Program of Scientific and Technology Project, Guilin Science Research and Technology Development (grant no. 2016012706-2), National Natural Science Foundation of China (grant no. 81460038) and Guangxi Natural Science Foundation of China (grant no. 2017GXNSFAA198178).

\section{Availability of data and materials}

The datasets used and/or analyzed during the present study are available from the corresponding author on reasonable request.

\section{Authors' contributions}

YRL, ZPG and ZZY conceived and designed the study, as well as desiged the figures and tables. FXZ, XTW and ZZY contributed to the statistical analysis, as well as writing and correcting the manuscript. All authors read and approved the final manuscript.

\section{Ethics approval and consent to participate}

Not applicable.

\section{Patient consent for publication}

Not applicable.

\section{Competing interests}

The authors declare that they have no competing interests.

\section{References}

1. Xue JY, Huang C, Wang W, Li HB, Sun M and Xie M: HOXA11-AS: A novel regulator in human cancer proliferation and metastasis. Onco Targets Ther 11: 4387-4393, 2018.

2. Huang H, Sun J, Sun Y, Wang C, Gao S, Li W and Hu JF: Long noncoding RNAs and their epigenetic function in hematological diseases. Hematol Oncol 37: 15-21, 2019.

3. Jia L, Zhang Y, Tian F, Chu Z and Xin H: Long noncoding RNA colon cancer associated transcript- 1 promotes the proliferation, migration and invasion of cervical cancer. Mol Med Rep 16: 5587-5591, 2017

4. Zhang R and Xia T: Long non-coding RNA XIST regulates PDCD4 expression by interacting with miR-21-5p and inhibits osteosarcoma cell growth and metastasis. Int J Oncol 51: 1460-1470, 2017

5. Li Z, Jiang X, Su Z, Li J, Kang P, Li C and Cui Y: Current insight into a cancer-implicated long noncoding RNA ZFAS1 and correlative functional mechanisms involved. Pathol Res Pract 214: 1517-1523, 2018.

6. Cai B, Zheng Y, Ma S, Xing Q, Wang X, Yang B, Yin G and Guan F: BANCR contributes to the growth and invasion of melanoma by functioning as a competing endogenous RNA to upregulate Notch 2 expression by sponging miR204. Int J Oncol 51: 1941-1951, 2017.

7. Ohtsuka M, Ling H, Ivan C, Pichler M, Matsushita D, Goblirsch M, Stiegelbauer V, Shigeyasu K, Zhang X, Chen M, et al: H19 noncoding RNA, an independent prognostic factor, regulates essential Rb-E2F and CDK8- $\beta$-catenin signaling in colorectal cancer. EBioMedicine 13: 113-124, 2016.

8. Ling ZA, Xiong DD, Meng RM, Cen JM, Zhao N, Chen G, Li RL and Dang YW: LncRNA NEAT1 promotes deterioration of hepatocellular carcinoma based on in vitro experiments, data mining, and RT-qPCR analysis. Cell Physiol Biochem 48: $540-555,2018$.

9. Li BL and Wan XP: The role of lncRNAs in the development of endometrial carcinoma. Oncol Lett 16: 3424-3429, 2018.

10. Zhu Y, Chen P, Gao Y, Ta N, Zhang Y, Cai J, Zhao Y, Liu S and Zheng J: MEG3 activated by Vitamin D inhibits colorectal cancer cells proliferation and migration via regulating clusterin. EBioMedicine 30: 148-157, 2018.

11. Lu Q, Yu T, Ou X, Cao D, Xie T and Chen X: Potential lncRNA diagnostic biomarkers for early gastric cancer. Mol Med Rep 16: 9545-9552, 2017.

12. Xiong DD, Li ZY, Liang L, He RQ, Ma FC, Luo DZ, Hu XH and Chen G: The LncRNA NEAT1 accelerates lung adenocarcinoma deterioration and binds to Mir-193a-3p as a competitive endogenous RNA. Cell Physiol Biochem 48: 905-918, 2018.

13. Sun W, Zu Y, Fu X and Deng Y: Knockdown of lncRNA-XIST enhances the chemosensitivity of NSCLC cells via suppression of autophagy. Oncol Rep 38: 3347-3354, 2017. 
14. Dong H, Jiang S, Fu Y, Luo Y, Gui R and Liu J: Upregulation of lncRNA NR_046683 serves as a prognostic biomarker and potential drug target for multiple myeloma. Front Pharmacol 10: 45, 2019.

15. Butova R, Vychytilova-Faltejskova P, Souckova A, Sevcikova $S$ and Hajek R: Long non-coding RNAs in multiple myeloma. Noncoding RNA 5: pii: E13, 2019.

16. $\mathrm{Yu} \mathrm{T}, \mathrm{Xu} \mathrm{Z}$, Zhang $\mathrm{X}$, Men $\mathrm{L}$ and Nie $\mathrm{H}$ : Long intergenic non-protein coding RNA 152 promotes multiple myeloma progression by negatively regulating microRNA-497. Oncol Rep 40: 3763-3771, 2018.

17. Zhao Y, Xie Z, Lin J and Liu P: MiR-144-3p inhibits cell proliferation and induces apoptosis in multiple myeloma by targeting c-Met. Am J Transl Res 9: 2437-2446, 2017.

18. Xia J, Xu H, Zhang X, Allamargot C, Coleman KL, Nessler R, Frech I, Tricot G and Zhan F: Multiple myeloma tumor cells are selectively killed by pharmacologically-dosed ascorbic acid. EBioMedicine 18: 41-49, 2017.

19. Zhao Y, Zhang E, Lv N, Ma L, Yao S, Yan M, Zi F, Deng G, Liu X, He J, et al: Metformin and FTY720 synergistically induce apoptosis in multiple myeloma cells. Cell Physiol Biochem 48: 785-800, 2018.

20. Knief J, Reddemann K, Gliemroth J, Brede S, Bartscht T and Thorns C: ERG expression in multiple myeloma-A potential diagnostic pitfall. Pathol Res Pract 213: 130-132, 2017.

21. Chen R, Zhang X, Gao C, Luan C, Wang Y and Chen B: Treatment and prognostic factors for survival in newly diagnosed multiple myeloma patients with bortezomib and dexamethasone regimen: A single Chinese center retrospective study. Cancer Manag Res 9: 373-380, 2017.

22. Jin J, Wang T, Wang Y, Chen S, Li Z, Li X, Zhang J and Wang J: SRC3 expressed in BMSCs promotes growth and migration of multiple myeloma cells by regulating the expression of $\mathrm{Cx} 43$. Int J Oncol 51: 1694-1704, 2017.

23. Joao C, Bergantim R, Neves M, Chacim S, Afonso C, Barradas J, Bernardo M, Coelho H, Esteves G, Fraga C, et al Multiple myeloma in elderly patients-a Portuguese multicentric real-life study. Ann Hematol 98: 1689-1701, 2019.

24. Nooka AK, Kaufman JL, Hofmeister CC, Joseph NS, Heffner TL, Gupta VA, Sullivan HC, Neish AS, Dhodapkar MV and Lonial S Daratumumab in multiple myeloma. Cancer 125: 2364-2382, 2019.

25. Song X, Wilson KL, Kagan J and Panjabi S: Cost of peripheral neuropathy in patients receiving treatment for multiple myeloma: A US administrative claims analysis. Ther Adv Hematol 10: 2040620719839025, 2019.

26. Chen WC, Kanate AS, Craig M, Petros WP and Hazlehurst LA: Emerging combination therapies for the management of multiple myeloma: The role of elotuzumab. Cancer Manag Res 9: 307-314, 2017.

27. Willenbacher W, Seeber A, Steiner N, Willenbacher E, Gatalica Z, Swensen J, Kimbrough J and Vranic S: Towards molecular profiling in multiple myeloma: A literature review and early indications of its efficacy for informing treatment strategies. Int J Mol Sci 19: pii: E2087, 2018.

28. Ribatti D and Vacca A: New insights in Anti-angiogenesis in multiple myeloma. Int J Mol Sci 19: pii: E2031, 2018.

29. Zeng ZH, Chen JF, Li YX, Zhang R, Xiao LF and Meng XY: Induction regimens for transplant-eligible patients with newly diagnosed multiple myeloma: A network meta-analysis of randomized controlled trials. Cancer Manag Res 9: 287-298, 2017.

30. Abramson HN: The multiple myeloma drug pipeline-2018: A review of small molecules and their therapeutic targets. Clin Lymphoma Myeloma Leuk 18: 611-627, 2018.

31. Handa H, Kuroda Y, Kimura K, Masuda Y, Hattori H, Alkebsi L, Matsumoto M, Kasamatsu T, Kobayashi N, Tahara KI, et al: Long non-coding RNA MALAT1 is an inducible stress response gene associated with extramedullary spread and poor prognosis of multiple myeloma. Br J Haematol 179: 449-460, 2017.

32. Hu Y, Lin J, Fang H, Fang J, Li C, Chen W, Liu S, Ondrejka S, Gong Z, Reu F, et al: Targeting the MALAT1/PARP1/LIG3 complex induces DNA damage and apoptosis in multiple myeloma. Leukemia 32: 2250-2262, 2018.

33. Ronchetti D, Agnelli L, Taiana E, Galletti S, Manzoni M, Todoerti K, Musto P, Strozzi F and Neri A: Distinct lncRNA transcriptional fingerprints characterize progressive stages of multiple myeloma. Oncotarget 7: 14814-14830, 2016.

34. Geng W, Guo X, Zhang L, Ma Y, Wang L, Liu Z, Ji H and Xiong Y: Resveratrol inhibits proliferation, migration and invasion of multiple myeloma cells via NEAT1-mediated Wnt/ $\beta$-catenin signaling pathway. Biomed Pharmacother 107: 484-494, 2018.
35. Wu Y and Wang H: LncRNA NEAT1 promotes dexamethasone resistance in multiple myeloma by targeting miR-193a/MCL1 pathway. J Biochem Mol Toxicol: 32, 2018.

36. Zhang ZS, Wang J, Zhu BQ and Ge L: Long noncoding RNA UCA1 promotes multiple myeloma cell growth by targeting TGF- $\beta$. Eur Rev Med Pharmacol Sci 22: 1374-1379, 2018.

37. Yang X, Ye H, He M, Zhou X, Sun N, Guo W, Lin X, Huang H, Lin Y, Yao R and Wang H: LncRNA PDIA3P interacts with $\mathrm{c}-\mathrm{Myc}$ to regulate cell proliferation via induction of pentose phosphate pathway in multiple myeloma. Biochem Biophys Res Commun 498: 207-213, 2018

38. Sun Y, Pan J, Zhang N, Wei W, Yu S and Ai L: Knockdown of long non-coding RNA H19 inhibits multiple myeloma cell growth via NF-кB pathway. Sci Rep 7: 18079, 2017.

39. Chen $\mathrm{L}, \mathrm{Hu} \mathrm{N}$, Wang $\mathrm{C}$, Zhao $\mathrm{H}$ and $\mathrm{Gu}$ Y: Long non-coding RNA CCAT1 promotes multiple myeloma progression by acting as a molecular sponge of miR-181a-5p to modulate HOXA1 expression. Cell Cycle 17: 319-329, 2018.

40. Meng YB, He X, Huang YF, Wu QN, Zhou YC and Hao DJ: Long noncoding RNA CRNDE promotes multiple myeloma cell growth by suppressing miR-451. Oncol Res 25: 1207-1214, 2017.

41. He RQ, Zhou XG, Yi QY, Deng CW, Gao JM, Chen G and Wang QY: Prognostic signature of alternative splicing events in bladder urothelial carcinoma based on spliceseq data from 317 cases. Cell Physiol Biochem 48: 1355-1368, 2018.

42. Formicola D, Petrosino G, Lasorsa VA, Pignataro P, Cimmino F, Vetrella S, Longo L, Tonini GP, Oberthuer A, Iolascon A, et al: An 18 gene expression-based score classifier predicts the clinical outcome in stage 4 neuroblastoma. J Transl Med 14: $142,2016$.

43. Zhou M, Zhang Z, Zhao H, Bao S and Sun J: A novel lncRNA-focus expression signature for survival prediction in endometrial carcinoma. BMC Cancer 18: 39, 2018.

44. Kim HY, Lee DH, Lee JH, Cho YY, Cho EJ, Yu SJ, Kim YJ and Yoon JH: Novel biomarker-based model for the prediction of sorafenib response and overall survival in advanced hepatocellular carcinoma: A prospective cohort study. BMC Cancer 18: 307, 2018

45. Liang L, Zeng JH, Qin XG, Chen JQ, Luo DZ and Chen G: Distinguishable prognostic signatures of left- and right-sided colon cancer: A study based on sequencing data. Cell Physiol Biochem 48: 475-490, 2018.

46. Edgar R, Domrachev M and Lash AE: Gene expression omnibus: NCBI gene expression and hybridization array data repository. Nucleic Acids Res 30: 207-210, 2002.

47. Barrett T, Wilhite SE, Ledoux P, Evangelista C, Kim IF, Tomashevsky M, Marshall KA, Phillippy KH, Sherman PM, Holko M, et al: NCBI GEO: Archive for functional genomics data sets-update. Nucleic Acids Res 41 (Database Issue): D991-D995, 2013.

48. Shi L, Campbell G, Jones WD, Campagne F, Wen Z, Walker SJ, Su Z, Chu TM, Goodsaid FM, Pusztai L, et al: The microarray quality control (MAQC)-II study of common practices for the development and validation of microarray-based predictive models. Nat Biotechnol 28: 827-838, 2010.

49. O'Leary NA, Wright MW, Brister JR, Ciufo S, Haddad D, McVeigh R, Rajput B, Robbertse B, Smith-White B, Ako-Adjei D, et al: Reference sequence (RefSeq) database at NCBI: Current status, taxonomic expansion, and functional annotation. Nucleic Acids Res 44: D733-D745, 2016.

50. Zerbino DR, Achuthan P, Akanni W, Amode MR, Barrell D, Bhai J, Billis K, Cummins C, Gall A, Girón CG, et al: Ensembl 2018. Nucleic Acids Res 46: D754-D761, 2018.

51. Liu J, Lichtenberg T, Hoadley KA, Poisson LM, Lazar AJ, Cherniack AD, Kovatich AJ, Benz CC, Levine DA, Lee AV, et al: An integrated TCGA pan-cancer clinical data resource to drive high-quality survival outcome analytics. Cell 173: 400-416.e11, 2018.

52. Ioannidis JPA: The proposal to lower $P$ value thresholds to .005 . JAMA 319: 1429-1430, 2018.

53. Kanehisa M, Sato Y, Furumichi M, Morishima K and Tanabe M: New approach for understanding genome variations in KEGG. Nucleic Acids Res 47: D590-D595, 2019.

54. Kanehisa M, Furumichi M, Tanabe M, Sato Y and Morishima K: KEGG: New perspectives on genomes, pathways, diseases and drugs. Nucleic Acids Res 45: D353-D361, 2017.

55. Kanehisa M and Goto S: KEGG: Kyoto encyclopedia of genes and genomes. Nucleic Acids Res 28: 27-30, 2000.

56. Yu G, Wang LG, Han Y and He QY: clusterProfiler: An R package for comparing biological themes among gene clusters. OMICS 16: 284-287, 2012. 
57. Warde-Farley D, Donaldson SL, Comes O, Zuberi K, Badrawi R, Chao P, Franz M, Grouios C, Kazi F, Lopes CT, et al: The GeneMANIA prediction server: Biological network integration for gene prioritization and predicting gene function. Nucleic Acids Res 38: W214-W220, 2010.

58. Shannon P, Markiel A, Ozier O, Baliga NS, Wang JT, Ramage D, Amin N, Schwikowski B and Ideker T: Cytoscape: A software environment for integrated models of biomolecular interaction networks. Genome Res 13: 2498-2504, 2003.

59. Lin P, He RQ, Ma FC, Liang L, He Y, Yang H, Dang YW and Chen G: Systematic analysis of survival-associated alternative splicing signatures in gastrointestinal pan-adenocarcinomas. EBioMedicine 34: 46-60, 2018.

60. Liu LM, Xiong DD, Lin P, Yang H, Dang YW and Chen G: DNA topoisomerase 1 and $2 \mathrm{~A}$ function as oncogenes in liver cancer and may be direct targets of nitidine chloride. Int J Oncol 53: 1897-1912, 2018.

61. Langfelder P and Horvath S: WGCNA: An R package for weighted correlation network analysis. BMC Bioinformatics 9: 559, 2008.

62. Langfelder P and Horvath S: Fast R functions for robust correlations and hierarchical clustering. J Stat Softw 46: pii: i11, 2012.

63. Hu AX, Huang ZY, Zhang L and Shen J: Potential prognostic long non-coding RNA identification and their validation in predicting survival of patients with multiple myeloma. Tumour Biol 39: 1010428317694563, 2017.

64. Zhou M, Zhao H, Wang Z, Cheng L, Yang L, Shi H, Yang H and Sun J: Identification and validation of potential prognostic lncRNA biomarkers for predicting survival in patients with multiple myeloma. J Exp Clin Cancer Res 34: 102, 2015.

65. Thierry G, Beneteau C, Pichon O, Flori E, Isidor B, Popelard F Delrue MA, Duboscq-Bidot L, Thuresson AC, van Bon BW, et al: Molecular characterization of 1q44 microdeletion in 11 patients reveals three candidate genes for intellectual disability and seizures. Am J Med Genet A 158A: 1633-1640, 2012.

66. Sutaria DS, Jiang J, Azevedo-Pouly ACP, Lee EJ, Lerner MR, Brackett DJ, Vandesompele J, Mestdagh P and Schmittgen TD: Expression profiling identifies the noncoding processed transcript of HNRNPU with proliferative properties in pancreatic ductal adenocarcinoma. Noncoding RNA 3: pii: E24, 2017.
67. He W, Wei D, Cai, Chen S, Li S and Chen W: Altered long non-coding RNA transcriptomic profiles in ischemic stroke. Hum Gene Ther 29: 719-732, 2018.

68. Liu YD, Li Y, Feng SX, Ye DS, Chen X, Zhou XY and Chen SL: Long noncoding RNAs: Potential regulators involved in the pathogenesis of polycystic ovary syndrome. Endocrinology 158: 3890-3899, 2017.

69. Low JS, Chin YM, Mushiroda T, Kubo M, Govindasamy GK, Pua KC, Yap YY, Yap LF, Subramaniam SK, Ong CA, et al: A genome wide study of copy number variation associated with nasopharyngeal carcinoma in Malaysian Chinese identifies CNVs at 11q14.3 and 6p21.3 as candidate loci. PLoS One 11: e0145774, 2016.

70. Simino J, Shi G, Arnett D, Broeckel U, Hunt SC and Rao DC: Variants on chromosome 6p22.3 associated with blood pressure in the HyperGEN study: Follow-up of FBPP quantitative trait loci. Am J Hypertens 24: 1227-1233, 2011.

71. Pei G, Lan Y, Chen D, Ji L and Hua ZC: FAK regulates E-cadherin expression via p-SrcY416/p-ERK1/2/p-Stat3Y705 and PPAR $\gamma / \mathrm{miR}-125 \mathrm{~b} / \mathrm{Stat} 3$ signaling pathway in B16F10 melanoma cells. Oncotarget 8: 13898-13908, 2017.

72. Hanahan D and Weinberg RA: Hallmarks of cancer: The next generation. Cell 144: 646-674, 2011.

73. Yao R, Sun X, Xie Y, Sun X, Yao Y, Li H, Li Z, Gao J and Xu K: Identification of a novel c-Myc inhibitor with anti-tumor effects on multiple myeloma cells. Biosci Rep 38: pii: BSR20181027, 2018.

74. Wang H, Ding Q, Wang M, Guo M and Zhao Q: miR-29b inhibits the progression of multiple myeloma through downregulating FOXP1. Hematology 24: 32-38, 2019.

75. Ronchetti D, Manzoni M, Todoerti K, Neri A and Agnelli L: In Silico characterization of miRNA and long non-coding RNA interplay in multiple myeloma. Genes (Basel) 7: pii: E107, 2016.

This work is licensed under a Creative Commons Attribution-NonCommercial-NoDerivatives 4.0 International (CC BY-NC-ND 4.0) License. 